\title{
A Educação Física Escolar "COM" a Educação Infantil: aproximações com Paulo Freire
}

\author{
Uirá de Siqueira Farias ${ }^{1}$ \\ Orcid: https://orcid.org/0000-0001-7286-1000 \\ Daniel Teixeira Maldonado ${ }^{2}$ \\ Orcid: https://orcid.org/0000-0002-0420-6490 \\ Valdilene Aline Nogueira ${ }^{3}$ \\ Orcid: http://orcid.org/0000-0002-5271-1635 \\ Graciele Massoli Rodrigues ${ }^{4}$ \\ Orcid: https://orcid.org/0000-0002-0275-0193
}

\begin{abstract}
Resumo
O objetivo deste estudo é apresentar uma experiência político-pedagógica de Educação Física Escolar "COM" a Educação Infantil, que tematizou a ginástica a partir de aproximações aos conceitos freirianos. A experiência pedagógica aconteceu no primeiro trimestre de 2019 com crianças de cinco anos de uma escola pública. As crianças puderam dizer a sua própria palavra e, dialogicamente, construíram as aulas de Educação Física, demonstrando a importância de uma escuta atenta às leituras de mundo que fazem. Práticas Político-Pedagógicas ancoradas nos conceitos freirianos potencializam inéditos viáveis mesmo diante de um sistema que impede os projetos coletivos, invalida os conhecimentos considerados mais relevantes pelas crianças e estabelece um currículo técnico-instrumental. Aproximar a Educação Física ao pensamento freiriano pode contribuir para um reposicionamento da função social do componente curricular em direção à Educação Libertadora.
\end{abstract}

Palavras-chave: Diálogo. Tematização. Autonomia.

\begin{abstract}
The aim of this study is to present a political-pedagogical experience of School Physical Education in Early Childhood Education that focused on gymnastics from approaches to Freire's concepts. The experience report was based on critical qualitative research, with a view to valuing counter-hegemonic science. The pedagogical experience took place in the first quarter of 2019 with five-year-old children from a public school. The children were able to say their own words and dialogically built the Physical Education classes, demonstrating the importance of listening attentively to the readings of the world that children. PoliticalPedagogical Practices anchored in Freire's concepts potentiate viable innovations even in the face of a system that prevents collective projects, invalidates the knowledge considered most relevant by children and establishes a technical-instrumental curriculum. Bringing Physical Education closer to Freire's thinking can contribute to a repositioning of the social function of the curricular component towards Liberating Education.
\end{abstract}

Keywords: Dialogue. Thematization. Autonomy.

\footnotetext{
${ }^{1}$ Mestre em Educação Física, Universidade São Judas, E-mail: uirasiqueira@yahoo.com.br

${ }^{2}$ Pós-Doutor em Educação, Instituto Federal de São Paulo, E-mail:danieltmaldonado@yahoo.com.br

${ }^{3}$ Mestra em Educação Física, Universidade São Judas, E-mail:valdilenenogueira@yahoo.com.br

${ }^{4}$ Doutora em Educação Física, Universidade São Judas, E-mail:prof.graciel@usjt.br

Pesquisa com apoio da Coordenação de Aperfeiçoamento de Pessoal de Nível Superior (CAPES).
} 


\title{
1 Primeiras palavras
}

$\mathrm{Eu}$ insistiria em que a origem do conhecimento está na pergunta, ou nas perguntas, ou no ato mesmo de perguntar; eu me atreveria a dizer que a primeira linguagem foi uma pergunta, a primeira palavra foi a um só tempo pergunta e resposta, num ato simultâneo. Eu não entendo a linguagem quando falo de linguagem, apenas a linguagem falada. Sabemos que a linguagem é de natureza gestual, corporal, é uma linguagem de movimento de olhos, de movimento do coração. A primeira linguagem é a do corpo e, na medida em que essa é uma linguagem de perguntas e na medida em que limitamos essas perguntas e não ouvimos ou valorizamos senão o que é oral ou escrito, estamos eliminando grande parte da linguagem humana (FREIRE; FAUNDEZ, 2013, 1. 859).

O diálogo tecido entre Freire e Faundez (2013) inspira esse relato de experiência: o ato de perguntar das crianças da Educação Infantil materializado nas perguntas corporais. A esse respeito, Kohan (2020), ao escrever sobre Paulo Freire, apresenta diversas relações com as infâncias, destacando que o patrono da educação brasileira sempre carregou consigo seu jeito menino, sua forma de ver essas infâncias: curiosa, inquieta e criativa. Fato esse que inclusive foi reconhecido pela Biblioteca de Comunale de Ponsacco, na Itália, que atribuiu a Freire o título de Menino Permanente.

Faundez em diálogo com Freire nos presenteia com essa visão enriquecedora dos gestos corporais para além de uma visão biológica, enaltecendo as linguagens e o ato de perguntar, como vemos em "dessas perguntas corporais que o corpo nos faz" (FREIRE; FAUNDEZ, 2013, 1. 858). Kohan (2020, p. 125) menciona que Paulo Freire, ao discutir a própria alfabetização e a sua visão sobre o tema, nos remete ao entendimento da linguagem do corpo como instância fecunda da humanidade, em que não existe dicotomia entre "mundo da vida e o mundo das letras". Assim, e com a epígrafe supracitada de Paulo Freire e Antonio Faundez (2013), somos convocados a repensar a nossa prática político-pedagógica quando anunciam a pedagogia da pergunta, evidenciando a grande importância da curiosidade para provocar o gosto pelo saber.

A obra organizada por Silva e Mafra (2020) reposiciona percepções ou nos apresentam indícios para se colocar de vez Paulo Freire e suas ideias nas discussões educacionais sobre a educação das crianças pequenas. Silva e Fasano (2020) destacam que a pedagogia da Libertação vai além de um olhar pedagógico voltado somente aos jovens e adultos, pois é uma epistemologia que pode contribuir com a educação das crianças da Educação Infantil. E é exatamente reconhecendo que as infâncias são oprimidas pela visão adultocêntrica, que Silva e Fasano (2020. p. 84) sugerem uma "Pedagogia da Infância Oprimida".

\begin{abstract}
De forma geral, na cultura ocidental, o mundo adulto se autorreferencia, oprimindo e desqualificando outras formas de ser e estar no mundo. Frente a isso, é preciso descentrar-se da leitura hegemônica adultocêntrica, identificando de uma maneira curiosa outros paradigmas de sentir, conceber e viver o mundo. Embora imersos em um contexto real, concreto e historicamente construído e não ignorando os nossos condicionamentos, somos desafiados epistemologicamente a emergir de tal contexto para, com criticidade, compreender a existência de outras formas de conceber e representar o mundo, buscando interagir com elas (SILVA; FASANO, 2020, p. 84).
\end{abstract}

Romper com uma visão adultocêntrica ao se trabalhar com as crianças da Educação Infantil é um grande desafio, porque é necessário fazer um exercício de revisitar a prática pedagógica com abertura ao novo e à autocrítica. É preciso dialogar com a própria infância que existe em cada um de nós adultos, pois a nossa adultez vem sendo forjada constantemente pelo sistema neoliberal que assola a nossa vida (SANTOS NETO; SILVA, 2008). 
Em tempos de "Educação S/A", como bem diz Bossle (2019, p. 21), e de ataques a Paulo Freire, nunca foi tão necessário publicizar o potencial de suas teses, ideia que também é afirmada por Vicente e Silva (2020), inclusive diante de um cenário de perigo contra a Educação, vinda de grupos neoconservadores que cultuam a negação da ciência/pesquisa (BOSSLE, 2019). Outro problema que vêm de forma sorrateira invadindo a Educação nacional com seu viés mercadológico pautado na eficácia, nas competências e habilidades, desconsiderando totalmente os/as docentes como intelectuais das realidades escolares é a Base Nacional Comum Curricular (BRASIL, 2017). Como nos traz Arroyo (2016), são os poderes que vem do alto que tentam estabelecer os ditames o tempo todo. Para Vicente e Silva (2020, p. 208) "a atualidade do pensamento de Paulo Freire nos convoca à necessidade política de reinventá-lo, para que possamos responder aos desafios deste tempo histórico", pois assim como as crianças, os/as educadores/as vêm sendo "amordaçados e silenciados" por essas forças (VICENTE; SILVA, 2020, p. 208).

Além disso, aproximar as obras de Paulo Freire e aquelas relacionadas a ele, é reconhecer um reposicionamento, é abrir possibilidades que tal literatura pode trazer para a área da Educação Física, e mais especificamente, o trabalho pedagógico com as crianças da Educação Infantil. Para Nogueira et al. (2018) essa aproximação se mostra pertinente com a constatação que a Educação Física pouco utiliza os escritos de Paulo Freire para compor a artesania das práticas pedagógicas na escola, campo em que o educador pode como ninguém ser fonte para reflexões, no sentido de contribuir na construção de uma escola mais crítica, libertária e emancipadora (FREIRE, 2013a; 2015). Mesmo assim, já é possível visualizar produções sobre o componente curricular encharcadas de pressupostos freirianos, como na recente obra de Sousa, Nogueira e Maldonado (2019).

As obras "Educação como prática da liberdade; Pedagogia do Oprimido; Pedagoga da Esperança e Pedagogia da Autonomia" de Paulo Freire, nos inspiram a evidenciar a preposição "COM" carregada de um sentido essencial em nossa escrita. Temos pensado esse "COM" como sinônimo de participação, de construções sempre em comunhão "COM" o outro, no e "COM" o mundo. É um "COM" carregado de politização, de luta, de engajamento, de emancipação e libertação do ser humano (FREIRE, 2013a; 2015). É um "COM" no sentido de "junto, juntamente, simultaneamente" (HOUAISS; VILLAR, 2010). Nos sentidos de companhia ("COM" o mundo), de união ("COM" o outro), de objetivo e propósito ("COM" a intenção de transformar o mundo junto "COM" as pessoas) (HOUAISS; VILLAR, 2010). Nas palavras de Freire:

Existir ultrapassa viver porque é mais do que estar no mundo. É estar nele e com ele. E é essa capacidade ou possibilidade de ligação comunicativa do existente com o mundo objetivo, contida na própria etimologia da palavra, que incorpora ao existir o sentido de criticidade que não há no simples viver. Transcender, discernir, dialogar (comunicar e participar) são exclusividades do existir. O existir é individual, contudo só se realiza em relação com outros existires (FREIRE, 2015, p. 84).

Assim, como em Santos Neto e Silva (2008, p. 112), defendemos uma pedagogia que precisa se fazer com os adultos e sua infância, com as crianças e sua infância. Sob esse contexto, a Educação Física Escolar "COM" a Educação Infantil ganha um valioso enredo com a presença da pedagogia freiriana em seus debates.

Estamos buscando em outras áreas de conhecimento como a Sociologia da Infância, a Pedagogia da Infância e a Educação, em autores como Sarmento (2013); Formosinho; Pascal (2019); Silva; Mafra (2020) fortalecer uma prática político-pedagógica da Educação Física que valorize e faça valer os direitos das crianças e suas infâncias (BRASIL, 2010; 2013), reconhecendo-as como sujeito real, integrante de uma grupo geracional - o da infância, agentes sociais, ativos e criativos, ou seja, não são apenas seres biológicos. Nesse sentido, as crianças 
são condutoras de suas infâncias. Assim, a infância é parte do ser humano, constitui sua história como seres produtores de conhecimento, de cultura e que leem o mundo à sua forma. A infância é, portanto, compreendida como condição de existência humana (SANTOS NETO; SILVA, 2008).

Dessa forma, a infância não significa apenas uma etapa cronológica da existência humana, e sim a própria condição para que possamos continuar vivendo, transformando, no cotidiano, a não-fala em língua e discurso capazes de colocá-los/as na posição de criadores de cultura (SANTOS NETO; SILVA, 2008, p. 114).

E é nessa postura sensível que vamos constituindo nossos olhares, uma construção coletiva, sempre inacabada "COM" as crianças, "COM" os/as agentes que fazem parte da instituição de Educação Infantil que atende as infâncias, ou seja, "COM" as pessoas. Para que todos e todas possam se sentir parte do mundo é necessário construir "COM" eles e elas o mundo. Sendo assim, esse "COM" vem carregado de política, de participação, de convocação e de comunhão, é a própria busca constante da educação como prática da liberdade (FREIRE, 2015).

Dessa forma, vale destacar que nas pedagogias participativas, tanto os/as educadores/as quanto as crianças estão "molhados" por experiências (FORMOSINHO; PASCAL, 2019). Experiências mergulhadas em desejos, imaginação, criatividade, sensibilidade e amorosidade, respeitando as singularidades, conscientes das imprevisibilidades e turbulências que a prática político-pedagógica encontra todos os dias. É preciso estarmos abertos e abertas à experiência. Não estamos falando de experimento, aquele que objetiva medir, quantificar e homogeneizar (SANTOS NETO; SILVA, 2008). É a experiencia que nos passa, que nos toca e que nos faz tremer o corpo (LARROSA, 2015).

Não estamos alheios aos condicionantes políticos que tentam o tempo todo atuar em nossas escolas. Não podemos, por mais difícil que seja, cair no determinismo, pois não devemos nos coisificar ou adaptar-se, e sim transformar a nossa realidade enquanto sujeitos da práxis (FREIRE, 2013a; 2015). É preciso uma vigília crítica constante do/da educador/a para não cair nas armadilhas da mercantilização da educação, na educação bancária. É necessário se contrapor a essa educação tão somente técnica que silencia a formação humana e suas dimensões política, ética e estética (SANTOS NETO; SILVA, 2008).

Existe aqui uma convocação aos professores e professoras de Educação Física Escolar, já que é necessário reposicionar nossas discussões e práticas pedagógicas quando se pensa a Educação Infantil. Mas não é um reposicionamento que vem de cima para baixo, dos acadêmicos/as para os/as educadores/as que estão nas escolas. É um voltar os nossos olhares para elas, "as crianças da Educação Infantil" e reconhecer-se criticamente sobre "si mesmos" enquanto educadores/as.

O que a Pedagogia da Infância Oprimida com atenção aos adultos vai pedir em especial dos/as educadores/as é que auxiliem os/as adultos/as a desaprenderem tudo aquilo que os/as levou a negar sua condição infantil e que, a partir daí, possam ajudálos/as a re-aprender a ler e a dizer o mundo desde suas próprias experiências (SANTOS NETO; SILVA, 2008, p. 119).

Por mais difícil que seja percebermos isso, a Educação Física Escolar não pode reproduzir as mesmas aulas que ocorrem em outros níveis da Educação Básica na Educação Infantil (EHRENBERG, 2014). É necessário esse reposicionamento: reconhecer e entender as crianças da Educação Infantil. É nas suas sensibilidades, ouvindo-as atentamente, construindo dialogicidade, na troca e na amorosidade que os conhecimentos que consideramos relevantes para o processo educativo ganha vida na Educação Física Escolar. 
"A criança compreendida por Freire é curiosa, perguntadeira e precisa de tempo e espaço para aprender" (SILVA; FASANO, 2020, p. 107). Então, vale permitir-se navegar "COM" elas, pela curiosidade, inventividade e criatividade, ou seja, pelo seu ser estético (SANTOS NETO; SILVA, 2008).

Postas essas reflexões, o objetivo do presente relato de experiência é apresentar uma prática político-pedagógica de Educação Física Escolar "COM" a Educação Infantil, que tematizou a ginástica se aproximando de conceitos freirianos.

\section{Caminhos metodológicos}

Nesse estudo, deixamos explícito que as crianças e suas infâncias são oprimidas pelo viés adultocêntrico, e com isso é negado a elas o seu direito de dizer a sua própria palavra, de serem ouvidas, de brincarem e se expressarem como seres produtores de conhecimento.

Vicente e Silva (2020) salientam que mesmo com os avanços nas discussões sobre os direitos das crianças, ainda existem instituições que caminham na contramão das pesquisas, com concepções reacionárias e que desqualificam as suas potencialidades. Então, acreditamos no diálogo como potente elemento de luta para reconhecer as crianças como seres autorais e que leem o mundo a seu modo.

Uma pedagogia que se desafia a ser crítica não terá um trabalho fácil pela frente, pois dar visibilidades as vozes e ouvir as crianças, requer de nós professores/as uma prática políticopedagógica ancorada na ideia de participação, autoria, criatividade, diálogo e emancipação. Nesse sentido, recorrer aos relatos de experiências significa um ótimo exercício de reflexão, além de representar a epistemologia da prática (DELMANTO; FAUSTINONI, 2009), trazendo a público as intenções e as vozes dos/das docentes e ainda, provocando o rompimento no sentimento de isolamento que muitos/as vivem nas realidades escolares.

$\mathrm{O}$ relato de experiência é um convite ao estudo de si mesmo (Self), podendo ser conduzido por narrativas e outros elementos que se complementam, como fotos, vídeos e as produções artísticas das crianças. Hernández (2008) fortalece essa ideia ao apontar como muito enriquecedor a interconexão de arte, imagens e textos nas pesquisas, pois a junção desses artefatos traz potentes significações e possibilita visualizar outras experiências, além de causar rupturas hegemônicas que permeiam as pesquisas. As imagens falam por si só, provocam as emoções e promovem formas diferentes de ver o mundo (HERNÁNDEZ, 2008).

Por questões éticas, vamos manter preservada a identidade das crianças, seus nomes serão fictícios e as imagens utilizadas passaram por modificações para ofuscar os seus rostos. Ainda, os responsáveis e as crianças assinaram os Termos de Anuência e Consentimento Livre e Esclarecido (TCLE). Além disso, para composição desse relato de experiência, utilizamos informações de notas de campo, os desenhos das crianças e vídeos feitos pelo professor durante as aulas da Educação Infantil em uma escola de Santo André-SP.

Esses elementos trazem aspectos que constituem de fato uma prática políticopedagógica que se aproximou das ideias de Paulo Freire e acima de tudo, demonstrou a imprevisibilidade, a vivacidade e dinamicidade que a realidade escolar nos submete todos os dias, ou seja, o saber da experiência vivida (FREIRE, 2015), que diante das situações limite, provocam o surgimento dos inéditos viáveis (FREIRE, 2013b).

\section{Dialogando com Paulo Freire}

A dimensão estética ganha relevo nessa experiência, pois acreditamos ser possível relacionar as ideias de Paulo Freire quando se trata da prática político-pedagógica da Educação Física "COM" a Educação Infantil, principalmente quando ele apresenta a criação humana, a boniteza das coisas, o potencial do ser humano de transformar o mundo, esteticamente 
deixando-o mais irradiante e humanizado (FREIRE, 2015; 2013b). E quem melhor que as crianças para deixar o mundo mais bonito, cheio de uma estética genial que se amplifica nessa fase da vida?

\begin{abstract}
Um sujeito estético pensa a si próprio e é, ao mesmo tempo, pensado pelos outros. É sujeito processual, porque vive em sociedade que também se faz e se refaz constantemente. Somos sujeitos estéticos na medida em que nos abrimos para novas possibilidades, novas práticas sociais, desfazendo-nos de referências cristalizadas. É necessário dar-se conta da esteticidade dessa sociedade, desbarrancando os antigos padrões de beleza, de harmonia, de linearidade e buscando nos microespaços, no cotidiano, nas frestas, as possíveis relações de sentido. É necessário buscar essa nova ética-estética nas frestas da sociedade atual (REDIN, 2010, p. 275).
\end{abstract}

As aulas com as crianças da Educação Infantil podem ser o maior espaço/tempo de criações autorais, pois diferente de nós adultos, pessoas que muitas vezes já perderam a meninice, como nos diz Kohan (2020), as crianças criam o tempo todo e das mais variadas formas que a gente pode imaginar, seja pela arte ou pela música, tudo se torna brincadeira. Além disso, as crianças, por meio das suas múltiplas linguagens não só reproduzem conhecimentos, mas também produzem cultura, leem, interpretam e transformam o mundo a sua maneira (CORSARO, 2011; VICENTE; SILVA, 2020).

Essa experiência pedagógica ocorreu durante o ano letivo de 2019, onde o professor tece reflexões críticas sobre sua prática. Para este relato é apresentada a discussão de uma tematização desenvolvida com as crianças no primeiro trimestre desse ano. Trata-se da prática político-pedagógica do professor do componente Educação Física e que leciona na turma de Educação Infantil, cenário onde o projeto educativo aqui relatado aconteceu. $\mathrm{O}$ professor também é autor desse trabalho e conta com a coautoria de três docentes que compartilharam as reflexões da construção da práxis.

A partir desde ponto, o texto será conduzido por um diálogo entre a narrativa do relato de experiência e algumas conversas com a literatura. Aqui queremos deixar explícito que a aproximação do docente que conduziu a práxis pedagógica com Paulo Freire vem de pesquisas sobre a Educação Física Escolar "COM" a Educação Infantil realizadas desde 2018, e que hoje estão presentes em grande parte das suas leituras, dos grupos de estudo que participa e das constantes trocas que realiza com colegas que estudam Paulo Freire, ou seja, é uma construção sempre constante e coletiva que nutrem a sua prática político-pedagógica.

A unidade escolar atende crianças de 4 a 11 anos, ou seja, desde a Educação Infantil até o $5^{\circ}$ ano das séries iniciais do fundamental. E como é comum acontecer em algumas escolas, logo no início do ano letivo toda a equipe escolar se reuniu para discutir o projeto político pedagógico (PPP), outros projetos específicos e acertar a parte burocrática que envolve o fazer pedagógico.

Após essa fase, iniciamos um processo que muitas vezes não fica explícito no dia a dia da escola: são as negociações de parcerias, a possibilidade de trabalhos compartilhados, ou o surgimento de projetos para as turmas. É bom ressaltar que não sabemos se isso é uma realidade de todos/as os/as docentes, porém, é uma iniciativa que nós tomamos no início de todos os anos. Empreitada que muitas vezes não tem sucesso, pois não são todos/as docentes que gostam de trabalhar com compartilhamento de projetos coletivos. É normal: a educação é uma construção constante, inclusive de relações pedagógicas.

Confessamos que sempre existe um estranhamento nos/nas colegas de trabalho quando realizamos propostas de trabalhos interdisciplinares com a Educação Física. Isso é compreensível, uma vez que a escola tem sido conduzida/cobrada por avaliações externas, como, por exemplo, o Programa Internacional de Avaliação de Alunos (PISA), que leva em consideração somente os conhecimentos das áreas de Português e Matemática. Um sistema 
vertical que não valoriza outros conhecimentos e inviabiliza pedagogias dialógicas (BOSSLE, 2019).

O resultado na escola não poderia ser outro, uma dificuldade no trabalho coletivo e dialógico. Mas, cientes dessas barreiras, temos nos motivado para sempre tentar. E em 2019, essa persistência deu bons resultados. Em diálogo com nossas colegas pedagogas da Educação Infantil, nos desafiamos a trabalhar de forma interdisciplinar. E que fique claro, não é a Educação Física trabalhando em detrimento das demais áreas. Foi um trabalho que tentou dialogar com os interesses das crianças, se atentando as suas falas, ouvindo-as, mas sem ausentar a intenção pedagógica que nós e as professoras tínhamos.

\begin{abstract}
Escutar as crianças e compreender o mundo a partir dos seus olhos implica no rompimento desse silenciamento, e, consequentemente, na construção de uma relação dialógica com elas, reconhecendo-as como participantes ativas da e na sociedade, o que se constituiu como um grande desafio frente a esta sociedade adultocêntrica (VICENTE; SILVA, 2020, p. 207).
\end{abstract}

Tomando a escuta como elemento importante de nossa prática político-pedagógica, e na busca por um projeto comum às áreas, uma das colegas pedagogas propôs um projeto que trouxesse a ideia da "transformação das coisas", por exemplo, papeis que poderiam se transformar em arte, a própria construção de uma peteca, ou as diversas formas que uma corda pode se tornar. E esse ficou sendo o projeto da Educação Infantil.

Mas afinal, o que a ginástica e as crianças "perguntadeiras" têm a ver com tudo isso? Estamos há 10 anos atuando em escolas públicas por alguns municípios de São Paulo, sempre com a Educação Infantil, e boa parte dessa atuação foi pautada por uma prática pedagógica que pouco ouvia as crianças, nada dialógica, onde circuitos e estafetas predominavam. Em 2016, mais precisamente com a nossa entrada no mestrado, começamos a rever nossas ações didáticas, questionando nossos pressupostos teóricos e ficando mais abertos ao novo, a outras possibilidades. Então, passamos a ler sobre a sociologia da infância, a pedagogia da infância, estudos da antropologia, alguns relatos de experiências publicados em revistas acadêmicas da Educação Física e assistir algumas apresentações em congressos, seminários e encontros pelo Brasil, percebendo que era necessário reposicionar nosso olhar para outras direções.

Nessas idas e vindas reflexivas, Paulo Freire começa a habitar nossas leituras, possibilitando outras interpretações para a prática na escola e com a Educação Infantil. Foi então que em 2019 decidimos produzir com as crianças as aulas de Educação Física. Planejamos três temas para aquele ano e o primeiro foi a ginástica. Mas por que a ginástica? Porque as crianças nos perguntavam o que era aquilo que as pessoas estavam fazendo em um ginásio que fica ao lado da quadra em que aconteciam algumas das nossas aulas. Ao lado da escola há um ginásio de Ginástica Artística para alto rendimento, com aparelhos como o solo, barras e argolas. Além disso, algumas crianças da nossa escola fazem aulas de iniciação nesse espaço, ou seja, está presente na cultura escolar falar de ginástica. Assim, essa prática corporal se tornou tema, pensado pedagogicamente para ser debatida dialogicamente com as crianças, no sentido de ampliar a visão de mundo que elas possuem dessa manifestação da cultural corporal (SANTOS; NEIRA, 2019). A tematização foi se constituindo a partir dos próprios conhecimentos das crianças, num movimento de escuta atenta daquilo que elas consideravam ser ginástica.

E essas "perguntadeiras" (as crianças) nos deram nesse primeiro dia de aula o start que faltava para de fato deixar que elas pronunciassem a sua palavra e pudéssemos ouvi-las mais atentamente. A respeito das "perguntadeiras", Silva e Fasano (2020) anunciam que Paulo Freire compreendia as crianças como esses seres da pergunta, seres humanos que por meio da curiosidade nos fazem muitas perguntas e que muitas vezes devemos nos silenciar para que elas possam falar, e mais do que isso, para que possamos ouvi-las. Esses autores evidenciam que 
não se trata de deixar as intenções pedagógicas, mas sim se atentar às relações que estabelecemos mutuamente (SILVA; FASANO, 2020).

Em Educação como Prática da Liberdade, Freire (2015) menciona sobre a participação das pessoas na construção de uma sociedade. Ao ler isso, ficamos pensando como efetivar essa participação com as crianças. Compreendemos que era necessário iniciar uma construção "COM" elas. Temos vivido com essas crianças construções pedagógicas em que vamos conversando sobre a ginástica que elas conhecem. São os seus conhecimentos, suas curiosidades, seus interesses sobre a ginástica em constante diálogo conosco. Não seria essa uma possibilidade para a Educação Infantil? Não devemos permitir a construção diária de uma escola para as infâncias "COM" elas?

Se na verdade, o sonho que nos anima é democrático e solidário, não é falando aos outros, de cima para baixo, sobretudo, como se fôssemos os portadores da verdade a ser transmitida aos demais, que aprendemos a escutar, mas é escutando que aprendemos a falar com eles. Somente quem escuta paciente e criticamente o outro, fala com ele, mesmo que em certas condições, precise falar a ele (FREIRE, 2011, p. 98-99).

Foi nessa construção diária que o nosso planejamento se tornou vivo, já que passamos a considerar as ideias das crianças. Fomos aprendendo "COM" as crianças esse difícil movimento inicial. Entendemos que a educação é política e possibilita uma prática crítica que precisa aguçar a curiosidade crítica com as crianças, construindo um sentimento aventureiro para nossas aulas (FREIRE, 2011).

Motivados pela curiosidade das crianças, chegamos na sala da turma e perguntamos a elas o que era ginástica. Uma avalanche de falas cobriu o ambiente e nos demos conta que deveríamos ter feito um combinado com elas. Mas mesmo nesse cenário captamos várias falas que com certeza fariam parte das próximas aulas. Fomos acalmando-as e conseguimos estabelecer o combinado da escuta. Voltamos a perguntar o que era ginástica. Dessa vez conseguimos chegar a um consenso e todas puderam falar. Nesse momento ficou nítido a visão de mundo e a leitura que elas faziam dessa manifestação da cultura corporal, já que as crianças apontaram diversas coisas que não estariam no nosso planejamento como sendo considerado ginástica (fala das crianças):

Ginástica é pular corda; Ginástica é correr; Ginástica é brincar de bambolê,; Ginástica é fazer estrelinha; Ginástica é fazer isso (a criança demonstrou uma flexão de braço); Ginástica e fazer ioga; Ginástica é pular; Ginástica é jogar bola com a mão; Ginástica é rolar no chão (ou na cama também); Ginástica é dançar; Brincar também é ginástica professor! A gente fica suado.

Nesse momento, ficamos perplexos com a infinidade de conhecimentos que muitas vezes deixamos de vivenciar com as crianças, pois sempre estivemos muito presos às habilidades motoras básicas, programando todas as etapas das aulas de forma sempre muito rígida. Ao ler Pedagogia da Autonomia de Freire (2011), reflexões foram surgindo e nos possibilitaram pensar quando de fato acontece o processo de desenvolvimento da autonomia nas escolas?

Ninguém é autônomo primeiro para depois decidir. A autonomia vai se constituindo na experiência de várias, inúmeras decisões que vão sendo tomadas. Por que, por exemplo, não desafiar o filho, ainda criança, no sentido de participar da escolha da melhor hora para fazer seus deveres escolares? Por que o melhor tempo para essa tarefa é sempre o dos pais? Por que perder a oportunidade de ir sublimando aos filhos o dever e o direito que eles têm, como gente, de ir forjando sua própria autonomia? (FREIRE, 2011, p. 93). 
Paulo Freire reflete sobre a ideia de as pessoas serem tratadas como coisas (coisificação) ao invés de sujeitos, de seres no mundo e com o mundo (FREIRE, 2015). Tal aspecto foi nos convidando nesse movimento de reflexão sobre considerar as crianças como sujeitos que participam da construção das aulas. Nesse contexto, um dos primeiros desejos das crianças era aprender a pular corda, e como elas já tinham estabelecido que pular corda era ginástica, fizemos um combinado incrível. Todos os dias a aula deveria iniciar com 15 minutos de corda. Portanto, estabelecemos que uma criança a cada dia ficaria responsável por chegar na quadra e distribuir as cordas para cada colega e após o tempo combinado essa mesma criança se encarregava de guardá-las.

Figura 1: Ginástica é brincar de corda

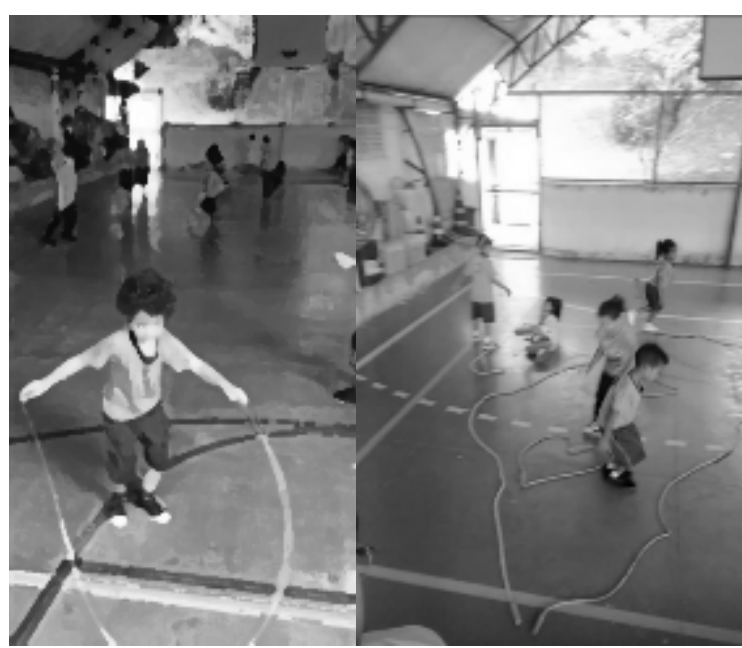

Fonte: Os/as autores/as

$\mathrm{Na}$ figura 1, apresentamos dois momentos distintos em que as aulas de ginástica aconteceram com muitas brincadeiras de corda, desde a forma individual até os grupos, inclusive as cordas se tornavam imensas figuras em que a ideia proposta por elas era saltar dentro e fora das formas. Com isso o projeto transformação era agraciado de boniteza.

A cada aula realizada, as crianças notavam que podiam colocar suas ideias. Criamos um vínculo de confiança, de amorosidade e carinho que se traduzia em aulas bem alegres, com direito a música em quase todas elas. Foi um misto de brincadeiras de ginástica musicada. Em uma das aulas o Pedro mencionou que adorava a Educação Física. Ficamos curiosos e logo devolvemos a seguinte pergunta: mas porque você gosta de Educação Física? Pedro, de forma muito simples, olhando nos nossos olhos, respondeu: porque sim. E saiu em suas contínuas tentativas de aprender a pular corda.

Freire (2011) valoriza o/a educador/a e sua prática; essa prática como dimensão estética, um ato de amorosidade, em que a alegria não necessita de se separar do rigor e da seriedade.

É preciso, por outro lado, reinsistir em que não se pense que a prática educativa vivida com afetividade e alegria prescinda da formação científica séria e da clareza política dos educadores ou educadoras. A prática educativa é tudo isso: afetividade, alegria, capacidade científica, domínio técnico a serviço da mudança ou, lamentavelmente, da permanência do hoje (FREIRE, 2011, p. 124).

E é exatamente essa preocupação de não se manter na permanência que a Educação Física necessita se engajar "COM" a Educação Infantil e romper com uma educação bancária, "friamente tecnicista", uma prática que acomoda, treina, transfere e conduz as crianças a meros “exercitadores de destrezas" (FREIRE, 2011, p. 125). 
As crianças têm nos motivado a não exercer uma educação anti-humanista e sim uma educação humanista, progressista, ciente do nosso inacabamento e que ao longo da vida vamos nos conscientizando, nos tornando seres conscientes (FREIRE, 2011). Independentemente da idade das crianças que vamos trabalhar, temos que ter consciência que a educação é uma ação que se faz com as pessoas, seres humanos em constante construção de seu ser, em constante busca (FREIRE, 2011). A educação é uma construção mútua entre educadores/as e educandos/as.

E nesse constante diálogo com as crianças vamos nos surpreendendo com suas perguntas, conhecimentos e constatações. Beatriz nos surpreende na sala perguntando se poderíamos fazer relaxamento. Então, perguntamos a ela: mas o que é relaxamento? Ela revirou os olhos e disse: ué, é ginástica! Tornamos a provocá-la: mas como podemos fazer o relaxamento aqui na sala? Beatriz responde de forma rápida e decisiva: vamos arrastar as mesas e colocar os tapetes ali. $A i$, você traz um som e coloca uma música tranquila, e todos podem se deitar. Diante de tal argumentação, não tivemos dúvidas e na aula seguinte voltamos mais cedo da quadra para vivenciarmos a proposta feita por Beatriz.

Por mais que o espaço da escola não fosse apropriado, as crianças ficaram extremamente felizes com a proposta. Além disso, essa prática do relaxamento passou a ser um momento bem presente em algumas das aulas, ao ponto de as professoras pedagogas colocarem na rotina das turmas da Educação Infantil. Aqui estamos procurando exercer a escuta atenta das crianças, fato que demonstra o como o planejamento dever ser sensível e se movimentar com os interesses delas em diálogo com a nossa intencionalidade político-pedagógica.

No prosseguimento da tematização, bem no trajeto entre a sala e a quadra, Manuela chama a atenção da turma toda: gente, temos que fazer uma aula de ioga! Professor, vamos fazer ioga? Não satisfeita, Manuela se sentou no chão, cruzou as pernas, fechou os olhos, uniu os dedos polegares e indicadores de cada mão e emitiu um som com a boca. Pronto, estava nos mostrando o que era ioga.

Mais uma aula em que fomos convocados a fazer. Perguntamos para a Manuela onde ela tinha visto essa ideia de ioga? Ela respondeu que assiste com sua mãe um programa de TV que tem aulas dessa prática corporal. Mas logo ressaltou: professor, é você que tem que ficar lá na frente fazendo os movimentos e as crianças devem seguir. Dissemos que não concordávamos em as crianças seguirem nossos movimentos, mas ela insistiu: não, você tem que pegar seu som e dar um tatame para cada criança e a gente segue os movimentos. Então, mais uma atividade de ginástica que foi proposta pela turma.

Figura 2: Temos que fazer ioga Professor!

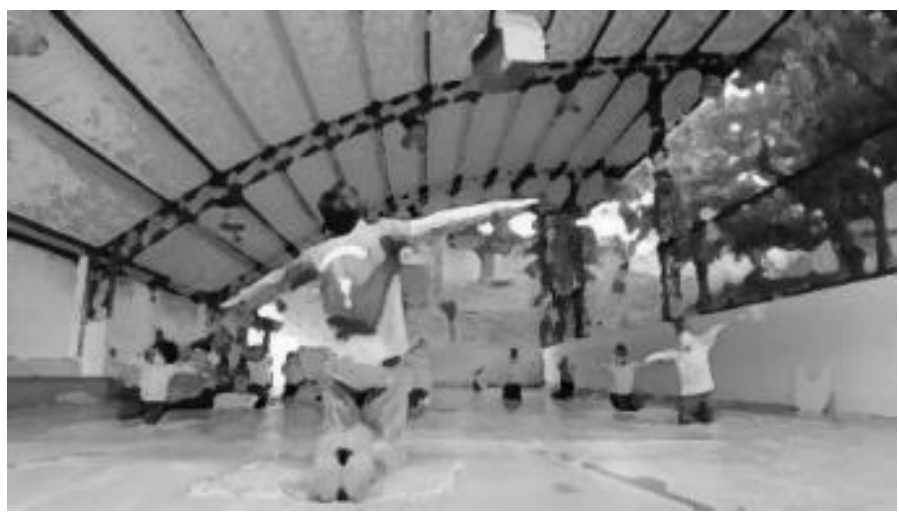

Fonte: Acervo dos autores/as

Aula após aula era um desafio. Fomos nos surpreendendo com tudo que aconteceu, mesmo com medo de não ter o controle de todos os momentos, nos desafiávamos cada dia mais 
e mais para dar possibilidades para elas criarem, construírem e se sentirem parte do nosso projeto educativo. Não é um processo fácil, significa quebrar a adultez, como bem apresentam Santos Neto e Silva (2008) e se jogar "COM" elas nessa aventura.

O projeto coletivo da Educação Infantil "Transformação" foi constantemente debatido nas nossas aulas. Sentávamo-nos em círculo, no pátio ou em qualquer outro lugar para conversarmos sobre como tudo que estávamos fazendo sofria um processo de transformação, nossos aprendizados, coisas que não sabíamos e agora sabemos mais um pouco, gestos que não sabíamos e que agora sabemos. Muitas vezes pensamos, de forma equivocada, que as crianças da Educação Infantil não captam esse processo, até o momento que você escuta a Larissa proferir a seguinte fala: professor a gente transforma o tempo todo. Larissa, toda confiante, após falar isso, saiu e foi transformar as coisas. E nós ficamos ali parados refletindo na genialidade que, com simplicidade, ela explicou o complexo.

Retomando aquelas ideias iniciais apontadas pelas crianças sobre o que era ginástica, os bambolês ganharam destaque, pois nessa escola temos aqueles bambolês que desmontam. Levamos a turma para a quadra e questionamos se todas as coisas se transformavam? Aquela típica chuva de falas foram tomando conta da nossa conversa. Provocamos elas a pensar nas transformações e nos usos que os bambolês poderiam possibilitar. Foi extraordinário ver a criatividade, os ajustes, as transformações, os conhecimentos que essas crianças produziram. Começaram a pegar as partes dos bambolês e unir umas às outras, construíram formas variadas, discos voadores, carros, trem, moedas e muitas outras coisas. O aluno Bruno ficou encantado quando conseguiu rodar o bambolê na sua cintura, veio por diversas vezes nos mostrar o que tinha criado, na sua fala: professor, professor, olha o que eu sei fazer, aprendi agora, sozinho. Nesse momento a turma toda ficou parada olhando o que o Bruno havia produzido. $\mathrm{Na}$ sequência, lá estava ele, ensinando seu novo conhecimento para as demais crianças.

Figura 3: Brincar de bambolê é ginástica (Formas, trem e bambolear na cintura).

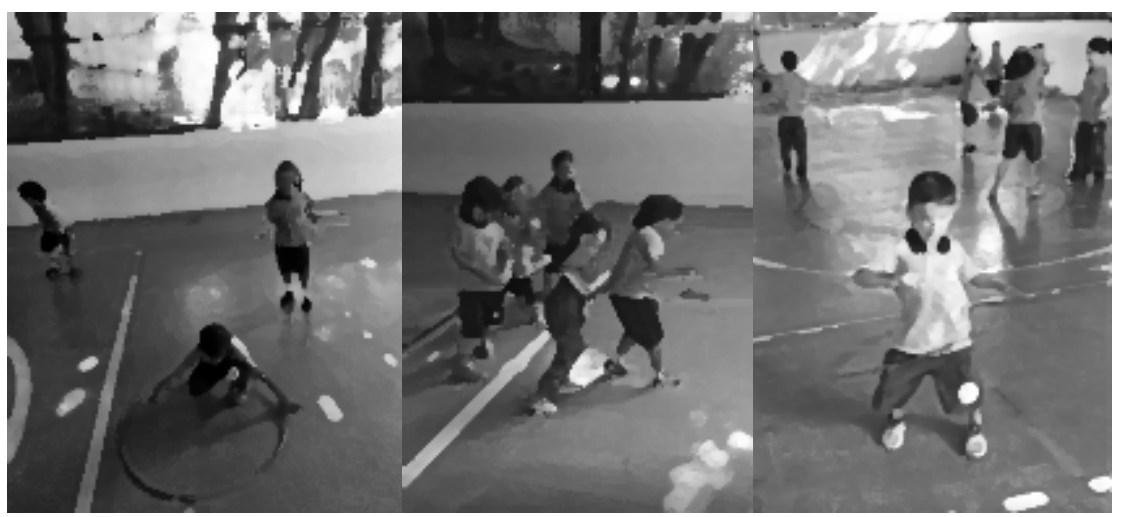

Fonte: Os/as autores/as

Até aqui muitas reflexões podem ser feitas, como as experiências e os sentidos que as crianças produzem no agora, ou seja, elas não estão pensando no amanhã. É rever a ideia de que o "pensar" está muito além somente do racionar, calcular e argumentar. Pensar, nas palavras de Bondía (2002, p. 21) é "dar sentido ao que somos e ao que nos acontece". É essa experiência que deve ser vivida, sem pressa, pois, a pressa é inimiga da experiência. Aprendemos tudo isso durante esse projeto, pois as crianças queriam mais tempo para explorar, criar suas hipóteses, experimentar o erro e construir seus conhecimentos. É a construção de sentido e significado que tem origem na visão de mundo delas, é a pura experiência vivida. Peloso e Paula (2020) trazem uma reflexão muito interessante sobre algumas obras de Paulo Freire quando ele remete os saberes das experiências feitas das crianças e a emancipação: 
Emancipação no sentido de que desde a infância o sujeito criança reconhecerá a história como possibilidade e por isso se constituirá como capaz de agir no mundo e transformá-lo. Freire deixou transparecer essa ideia em suas obras, nas quais a concepção de ser humano e a sua busca do ser mais constituem elementos de base de um processo educativo sustentado pela ação dialógica, pela apreciação dos contextos sócio-históricos e pela valorização dos saberes, de experiencias feitas das crianças e, ainda, pelo compromisso com a transformação das realidades. Uma prática que emancipa, que dá voz e sugere a autonomia das crianças para que sejam autoras de sua história e signifiquem o seu estar no mundo (PELOSO; PAULA, 2020, p. 222).

Encantado com a ideia do saber da experiência, na continuidade, as crianças nos chamaram a atenção para fazermos uma aula de estrelinha. Quando Luana escutou isso, logo executou esse gesto no pátio. E não foi uma estrelinha qualquer! Foi aquela feita com todo o detalhamento, desde a posição de preparação até a finalização. Luana possui uma irmã que faz ginástica, e logo abriu aquele sorriso, pois ela tinha convicção que tinha um conhecimento que dominava como ninguém. Perguntamos se ela poderia nos ensinar a fazer estrelinha. A alegria dessa menina foi tanta, que logo começou a falar como todos/as deveriam fazer.

Demos a ideia para que todos/as se sentassem para a Luana poder nos ensinar. Após tudo isso, mergulhado em um sentimento de muita alegria, ficamos sentados vendo a Luana mostrar seus conhecimentos. Conversamos com as crianças dando dicas iniciais para aqueles/aquelas que estavam mais inseguros. Depois disso, Luana foi de grupo em grupo, ajudando as crianças a aprenderem a estrelinha.

Sentimos que era necessário produzir registos variados com as crianças. As fotos e vídeos foram excelentes recursos para isso. Eles também serviram para uma avaliação desse processo. Mas também recorremos a uma roda de diálogo (MACHADO; FAGUNDES; SILVA, 2011) para que pudéssemos filmar a fala das crianças e suas mais variadas expressões sobre o que tinham aprendido sobre a ginástica. Então reunimos a turma na quadra e fizemos a seguinte provocação: o que aprendemos na Educação Física? Elas podiam demonstrar ou até falar suas impressões. É claro que todas quiseram demonstrar. E de forma organizada, cada criança podia ir até o centro do círculo e expressar suas aprendizagens (Figura 4).

Vários gestos vivenciados por elas durante a tematização da ginástica foram expressos nesse momento. Além da filmagem, fizemos outra produção por meio de desenhos. Nessa atividade, as crianças podiam fazer um desenho ou pintura da aula que elas mais gostaram durante o primeiro trimestre. Essa etapa foi realizada em conjunto com a pedagoga. Esses registros vão ficar guardados por muito tempo em nossos arquivos pessoais, pois representam um valor sentimental incalculável na nossa trajetória como docentes.

Figura 4: Registros pedagógicos feitos por meio dos desenhos e filmagens

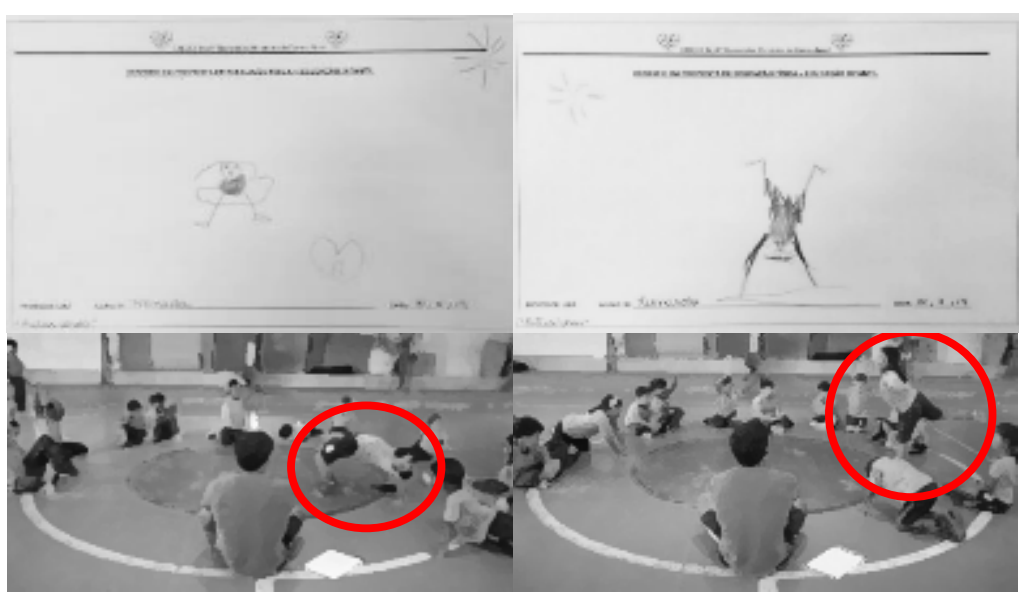

Fonte: Os/as autores/as 


\section{Reflexões construídas "COM" as crianças e aproximações freirianas}

Entendemos que aproximar a Educação Física Escolar da pedagogia de Paulo Freire representa um movimento de reposicionamento ou de recriação e redimensionamento, como aponta Peloso e Paula (2020), da práxis pedagógica com as crianças da Educação Infantil. Significa pensar uma prática político-pedagógica humanizadora, que acredita no ser humano, que entende as crianças no centro da produção de conhecimento. Essa experiência vivida de ter as crianças como centro colore a escola de perguntas, de hipóteses e de alegria. Tudo isso sem perder de vista a autoridade, a liberdade e a aprendizagem da democracia.

Lutar por uma educação emancipadora requer esforço contínuo dos/das educadores/as em promover situações concretas de aprendizagem envolvendo a democracia, independentemente da idade, raça ou gênero dos/das educandos/as (PELOSO; PAULA, 2020), pois estamos tratando essencialmente da vocação ontológica do ser humano, o "ser mais" (FREIRE, 2013a, p.117).

Quanto ao relato de experiência aqui narrado, representa um outro tipo de conhecimento. É aquele que foi produzido na realidade escolar, vestido de todas as imprevisibilidades que a escola possui. Também representa uma demarcação políticopedagógica que resiste a ação coercitiva de um sistema educacional nacional que apaga a ação de educadores/as pelo Brasil. Sistema esse que mata muitas vezes a autoria docente, impede os projetos coletivos, invalida os conhecimentos considerados mais relevantes pelas crianças e pelos/as docentes, e estabelece um currículo técnico-instrumental. Os relatos são outro tipo de ciência, uma ciência contra-hegemônica vivaz e dinâmica (SOUSA SANTOS, 2007; 2008).

Construir uma prática político-pedagógica "COM" as crianças não é tarefa fácil, requer utopia, esperançar e engajamento constante. Essa experiência não aconteceu sem tensionamentos, já que resistimos contra as forças de uma BNCC, as exigências e pressões para alfabetizar e calcular, sendo estes típicos conhecimentos mais valorizados pela sociedade ocidental.

Essas situações-limite foram um grande obstáculo para o projeto "Transformação", pois a ideia de integração interdisciplinar objetivava ao final do primeiro semestre, após o recesso de julho, expor as produções das crianças, como elementos da documentação pedagógica viva, que ficasse exposta para que as famílias e outras turmas pudessem ter contato com todo o acervo produzido. Porém, as pressões vindas tanto das famílias, como do sistema educacional para alfabetização e questões lógico-matemáticas foram enfraquecendo o projeto, ao ponto do diálogo entre nos educadores/as ficar restrito a corredores para organizarmos as ações. Esse é um exemplo para demonstrar como a lógica técnico-instrumental invade os currículos, promovendo a quebra de intenções pedagógicas construídas com muita luta. Continuar com o projeto foi sentir as situações-limite e mover o inédito viável como um gesto de resistência.

Materializando projetos pedagógicos como atos de criação de inéditos viáveis acreditamos que, ao se tratar da Educação Infantil, somos convocados a brincar e criar "COM" as crianças. Como seres no e com o mundo, as crianças, quando não oprimidas, emitem o seu grito político pelos seus direitos: é a teimosia curiosa e criativa de dizerem suas próprias palavras, ao ponto de convocarem seu ato de resistência por um mundo mais brincante, um mundo mais humano e amoroso, como bem afirmam Marques e Silva (2020).

E assim, por meio desse relato de experiência, buscamos aproximar Paulo Freire ao componente curricular Educação Física "COM” a Educação Infantil, espaço/tempo em que essas crianças "perguntaderias" podem brincar de transformar tudo na escola, inclusive a ginástica. 


\section{Referências}

ARROYO, M. G. Corpos resistentes produtores de culturas corporais. Haverá lugar na Base Nacional Cumum? Motrivivência, v. 28, n. 48, p. 15-31, 2016.

BONDÍA, J. L. Notas sobre a experiência e o saber de experiência. Revista Brasileira de Educação, v. 19, p. 20-28, 2002.

BOSSLE, F. Atualidade e relevância da Educação Libertadora de Paulo Freire na Educação Física Escolar em tempos de "Educação S/A". In: SOUSA, C. A. D.; NOGUEIRA, V. A.; MALDONADO, D. T. Educação Física Escolar e Paulo Freire: ações reflexões em tempos de chumbo. Curitiba: CRV, 2019. p. 17-32.

BRASIL. Diretrizes Curriculares Nacionais para a Educação infantil. Brasília: Ministério da Educação, 2010.

BRASIL. Diretrizes Curriculares Nacionais Gerais da Educação Básica. Brasília: Minitério da Educação. Secretaria de Educação Básica. Diretoria de Currículos e Educação Integral, 2013.

BRASIL. Base Nacional Comum Curricular. Brasília: Ministério da Educação, 2017.

CORSARO, W. Sociologia da infância. Porto Alegre: Artmed, 2011.

DELMANTO, D.; FAUSTINONI, L. E. Os relatos de prática e sua importância no processo de produção e socialização do conhecimento. In: SEE, S. D. E. D. E.- Currículo em debate: Relatos de práticas pedagógicas. Goiânia : Secretaria de Estado da Educação, 2009. p. 9-13.

DENZIN, N. K. Investigação Qualitativa Crítica. Sociedade, Contabilidade e Gestão. Rio de Janeiro, v. 13, n. 1, p. 1-15, 2018.

EHRENBERG, M. C. A linguagem da cultura corporal sob o olhar de professores da educação infantil. Pro-posições, São Paulo, v. 25, n. 1, p. 181-198, 2014.

FORMOSINHO, J. O.; PASCAL, C. Documentação pedagógica e avaliação na educação infantil. Porto Alegre: Penso, 2019.

FREIRE, P. Pedagogia da Autonomia: saberes necessários à Prática Educativa. 1. ed. São Paulo: Terra e Paz, 2011. Livro Digital.

FREIRE, P. Pedagogia do Oprimido. 1. ed. Rio de Janeiro: Paz e Terra, 2013a. Livro Digital.

FREIRE, P. Pedagogia da Esperança: um reencontro com a Pedagoia do Oprimido. 11. ed. Rio de Janeiro: Paz e Terra, 2013b. Livro Digital.

FREIRE, P. Educação Como Prática da Liberdade. 1. ed. Rio de Janeiro: Paz e Terra, 2015. Livro Digital.

FREIRE, P.; FAUNDEZ, A. Por uma pedagogia da pergunta. 1. ed. Rio de Janeiro: Paz e Terra, 2013. Livro Digital. 
HERNÁNDEZ, F. H. Lá investigación basada en las artes. Propuestas para repensar la investigación en educación. Educatio Siglo XXI, Barcelona, n. 26, p. 85-118, 2008.

HOUAISS, A.; VILLAR, M. D. S. Minidicionário Houaiss da língua portuguesa. 4a . ed. Rio de Janeiro: Objetiva, 2010.

KOHAN, W. O. Paulo Freire e a (sua) infância educadora. In: SILVA, M. R. P. D.; MAFRA, J. F. Paulo Freire e a Educação das crianças. São Paulo: BT Acadêmica, 2020, p. 122-147.

LARROSA, J. Tremores: Escritos sobre experiência. Belo Horizonte: Autêntica, 2015. Livro Digital.

MACHADO, R.; FAGUNDES, B.; SILVA, F. W. D. As crianças como autoras da significação da Educação Física. Motrivivência, v. XXIII, n. 37, p. 51-68, 2011.

MARQUES, R. F. B.; SILVA, M. R. P. D. Os círculos de cultura na Educação Infantil. In: SILVA, M. R. P. D.; MAFRA, J. F. Paulo Freire e a Educação das crianças. São Paulo: BT Acadêmicos, 2020. p. 225-252. Livro Digital.

NOGUEIRA, V. A. et al. Práticas Corporais e Paulo Freire: Uma análise sobre a produção do conhecimento. Movimento, Porto Alegre, v. 24, n. 4, p.1265 -1280, 2018.

PELOSO, F. C.; PAULA, E. M. T. A. D. Paulo Freire e as crianças: reflexões e olhares sobre a educação da infância. In: SILVA, M. R. P. D.; MAFRA, J. F. Paulo Freire e a educação das crianças. São Paulo: BT Acadêmica, 2020. p. 189-223. Livro Digital.

REDIN, M. M. Estética. In: STRECK, D. R.; REDIN, E.; ZITKOSKI, J. J. Dicionário Paulo Freire. 2a . ed. Belo Horizonte: Autêntica, 2010. p. 273-276.

SANTOS, I. L.; NEIRA, M. G. Tematização e problematização: pressupostos freirianos no currículo cultural da educação física. Pro-Posições. Campinas, v. 30, e20160168, 2019.

SANTOS NETO, E. D.; SILVA, M. R. P. D. Quebrando as armadilhas da "Adultez": um diálogo sobre infância a partir de Giorgio Agamben e Paulo Freire. Múltiplas Leituras, São Paulo, v. 1, n. 2, p. 111-123, 2008.

SARMENTO, M. J. A sociologia da infância e a sociedade contemporânea: desafios conceituais e praxeológicos. In: ENS, R. T.; GARANHANI, M. C. Sociologia da Infância e a formação de professores. São Paulo: Editora Universitária Champagnat, v. I, 2013, p. 13-46.

SILVA, M. R. P. D.; FASANO, E. Crianças e Infâncias em Paulo Freire. In: SILVA, M. R. P. D.; MAFRA, J. F. Paulo Freire e a Educação das Crianças. São Paulo: BT Acadêmicos, 2020, p. 83-121. Livro Digital.

SILVA, M. R. P. D.; MAFRA, J. F. Paulo Freire e a Educação das Crianças. São Paulo: BT Acadêmicos, 2020. Livro Digital.

SOUSA, C. A.; NOGUEIRA, V. A.; MALDONADO, D. T. Educação Física escolar e Paulo Freire: ações e reflexões em tempos de chumbo. Curitiba: CRV, 2019. 
SOUSA SANTOS, B. Para além do pensamento abissal: das linhas globais a uma ecologia de saberes. Revista Crítica de Ciências Sociais. v. 78, p. 3-46, 2007.

SOUSA SANTOS, B. Um discurso sobre as ciências. 5ª ed. São Paulo: Cortez, 2008.

VICENTE, A. D. J.; SILVA, M. R. P. D. A participação política das crianças pequenas na autoavaliação da qualidade da educação infantil: contribuições desde Paulo Freire. Educação \& Linguagem, v. 23, n. 2, p. 203-224, 2020. 